\title{
Jugar en contextos tecnológicos: uso y disfrute de internet por niños y niñas de 8 a 10 años en Argentina, Paraguay y Perú*
}

\author{
Rocío Trinidad (Pontificia Universidad Católica del Perú) \\ Natalia Zlachesvsky (Universidad de Buenos Aires, Argentina)
}

Recibido: 15/4/2013

Aprobado: 22/5/2013

Resumen: Para este artículo tomamos como fuente de análisis los hallazgos de la investigación comparativa «Uso y disfrute de internet por niños de 8 a 10 años en tres escuelas de Argentina, Paraguay y Perú». Allí encontramos que más allá de las diferencias y particularidades de los contextos nacionales, estos tienen en común que el uso y disfrute que los menores hacen de internet está marcado según clase, género, edad y nivel socioeconómico. En este caso analizaremos de qué manera estas variables intervienen y se combinan en el consumo cultural que los niños y las niñas hacen en contextos tecnológicos, dirigiendo sus deseos, fantasías y preferencias.

Palabras clave: Jugar / internet / niños

\section{Playing in technological contexts: Use and enjoyment of Internet by children ages eight to ten in Argentina, Paraguay and Peru}

Summary: This paper aims to analyse the relation between playing and cultural consumption in technological contexts through the experience and knowhow of boys and girls. We have taken as our analysis source the findings of the comparative investigation «Use and enjoyment of internet by children ages eight to ten in three schools in Argentina, Paraguay and Peru». We found that over and above the differences and particularities existing in each national context, countries have in common the use and enjoyment that boys and girls obtain out of surfing in the web, but this bears a mark in terms of class, gender, age and socioeconomic level. In this article we intend to analyse how these variables intervene and combine themselves in the cultural consumption that boys and girls perform in different technological contexts, directing their wishes, fantasies and preferences.

Keywords: Playing / internet / children

* Una versión preliminar de este artículo, «Playing in technological contexts», se presentó como ponencia en Bhubaneswar, India (30 de noviembre del 2012), en el Inter-congress of 


\section{Contexto actual: globalización y consumo}

$\mathrm{E}$ n el contexto político-económico global actual, la fluidez y las yuxtaposiciones imperan. La globalización económica coexiste con una fragmentación política en forma de bloques, donde paradójicamente las fronteras nacionales se desdibujan mientras que las fronteras de los bloques económicos se condensan. La cultura y la imaginación, que en el contexto «poselectrónico» tiene un papel «significativamente nuevo» (Appadurai 2001: 21), no escapan a la lógica del capitalismo tardío, ambas se han transformando de bienes de uso a bienes de cambio.

Entendemos lo cultural como una trama compleja de prácticas, creencias y significaciones y reconocemos el rol fundamental que cumple la industria cultural en el mundo contemporáneo. Esta industria, siguiendo a Renato Ortiz, produce repertorios simbólicos y los distribuye transnacionalmente estableciendo relaciones de jerarquía, hegemonizando y subalternizando unos sentidos sobre otros (Soto 2007). En consecuencia, consideramos que el éxito de la propagación del capitalismo, como sistema social, se debe a que «encuentra puntos de anclaje a nivel subjetivo» (Papalini 2008: 16). En este sentido, para los niños y niñas, la navegación y el consumo de productos culturales en internet constituyen una experiencia formativa en relación con la inmersión en el mundo del consumo. Como consumidores, desde edades cada vez más tempranas, su subjetividad se construye al ritmo del mercado.

Al respecto, destacamos el aporte que ha hecho Pierre Bourdieu en cuanto a la reproducción de la cultura hegemónica global. El autor destaca que lo simbólico tiene un rol fundamental en la forma de apropiación de bienes -desde los educacionales, artísticos, científicos, hasta la moda- y que ello contribuirá a «configurar las diferencias de clases» (García Canclini, citado por Vázquez s/f: 4). Por otro lado, las corrientes que interpretan la cultura desde un enfoque gramsciano han postulado la existencia de un interjuego entre los mecanismos de control y los procesos de resistencia. Nos interesa prestar atención a las apropiaciones que hacen los niños de los contenidos que reproducen ciertas categorías y nociones de la cultura hegemónica para preguntarnos acerca del margen de agencia que tienen en esos procesos.

Una muestra de ello, como veremos con amplitud en el acápite «Jugar en contextos tecnológicos», se eviden-

\footnotetext{
International Union of Anthropological and Ethnological Sciences (IUAES), international conference on "Children and Youth in a Changing World". Commission on Anthropology of Children, Youth and Childhood and the Kalinga Institute of Social Sciences (KISS), KIIT University, Bhubaneswar.
} 
cia en el uso que hacen los niños y las niñas de YouTube. En el visionado de videos, sus preferencias están focalizadas en el consumo de contenidos de la cultura popular, que recrean o parodian de forma libre contenidos de la industria cultural. Sin embargo, ellos construyen nuevas narrativas al seleccionar e interpretar los videos a partir de sus experiencias previas. Este proceso manifiesta el despliegue de prácticas lúdicas ad hoc, donde sus intereses, costumbres y saberes se relacionan activamente.

\section{El estudio y el contexto: internet en Argentina, Paraguay y Perú}

En los últimos años, la penetración de internet se ha expandido en todos los países latinoamericanos, aunque con algunas diferencias, que evidencian la desigualdad regional existente. A diciembre del 2011, según Internet World Stats (Miniwatts Marketing Group, en línea), la penetración de internet alcanzó la cota más alta en Argentina, donde el $66 \%$ de la población es usuaria de internet, en tanto en el Perú llega al 31,3 \% y en Paraguay al 17,1 \%.
Son las generaciones más jóvenes las que impulsan a las mayores a contar con el servicio de internet en sus hogares (Sádaba y Bringué 2009). Ello abundaría en la diferencia en la familiaridad con las nuevas tecnologías de la información y comunicación entre los nativos e inmigrantes digitales. ${ }^{1}$ No obstante, esta afirmación también podría relativizarse si tomamos en cuenta las diferencias socioeconómicas así como también las brechas digitales, en los ámbitos rurales y urbanos, existentes en el interior de los países en estudio.

El estudio sobre el cual trabajaremos indaga sobre el uso y disfrute de internet que hacen los niños desde los 8 hasta los 10 años en tres escuelas de diferentes niveles socioeconómicos de Argentina, Paraguay y Perú. El interés de aproximarnos a las realidades de estos tres países se relaciona con el fenómeno de la «migración posindustrial» que se evidencia en la migración sur-sur (Caggiano 2005: 30) y en el «ensanchamiento de la brecha entre países». ${ }^{2}$

La mencionada investigación tuvo un componente cualitativo y cuanti-

1 Se refiere a las categorías de Marc Prensky, quien distingue entre «nativos» e «inmigrantes digitales». Los primeros son los que han nacido y se han formado usando la «lengua digital»; los segundos son quienes, obligados por la necesidad, se han formado en ese lenguaje. Para mayor información consultar Prensky (2001).

2 El Producto Bruto Interno (PBI) al 2011 de Argentina y el Perú es de 4,5, mientras que el de Paraguay es de 3,0 (García 2011). De acuerdo con América Económica (en línea), Argentina y Perú, a diferencia de Paraguay, se encuentran entre los cinco países latinoamericanos con mayor crecimiento en el 2011. 
tativo. Se aplicaron 1088 encuestas a niños y niñas de tres colegios (de nivel socioeconómico medio, alto, bajo de Argentina, Paraguay y Perú, respectivamente; que de ahora en adelante identificaremos como CA, CB y CC) ubicados en zonas urbanas de las ciudades capital: Buenos Aires, Lima y Asunción. Se realizaron también talleres de observación de navegación libre en los que se observó un total de 94 niños y niñas de tercer grado y se entrevistó a 27 docentes, hombres y mujeres.

En el contexto urbano latinoamericano existe una tendencia al repliegue al ámbito doméstico, una suerte de confinamiento al ámbito privado. Así, en el estudio realizado la mayoría de los niños manifestó que accedían a internet desde sus casas y en soledad $(86,5 \%$ en Argentina, 70,4 \% en Paraguay y $76,2 \%$ en el Perú). Haciendo el desagregado por colegios, es importante señalar que en los tres países participantes los encuestados de los colegios de nivel socioeconómico más bajo fueron los que menos se conectaban desde sus casas en esas condiciones.

En relación con las nuevas tecnologías y la educación, han surgido en los últimos años, en la región, políticas de
Estado orientadas a la inclusión de las TIC en el ámbito escolar. ${ }^{3}$ El estudio realizado reveló que en Paraguay y el Perú el colegio representa el segundo lugar desde donde se conectan los niños (50,3 \% y 35,1 \%, respectivamente). Si bien la investigación no estaba focalizada específicamente en este tema, una metalectura de los resultados y una reflexión de la experiencia en la que hemos participado nos ha permitido indagar por la relación de los niños y las niñas con el aprendizaje, el juego y el jugar en internet. Veamos a continuación algunos hallazgos.

La propuesta de jugar libremente en el ámbito escolar reveló una tensión entre la norma y la libertad. Hay una suerte de picardía entre los niños cuando acceden a sitios no diseñados exclusivamente para niños, dentro de la escuela como espacio controlado en el que el uso de las herramientas web no se asemeja al que lo niños hacen espontáneamente.

Esta tensión se manifestó expresamente a través de un niño del colegio CA de Argentina que cuando contó que entraba a YouTube y se le preguntó por qué no lo había hecho durante el taller, respondió "porque estamos en la escuela», y después de la entrevista manifestó que se había topado

3 El Plan Ceibal, en Uruguay, que entrega una netbook por niño a todas las escuelas primarias y secundarias desde el año 2007; el Programa Conectar Igualdad, que entregará tres millones de netbooks a todas las escuelas secundarias en Argentina, y el programa Una Laptop por Niño, desde el 2008, en el Perú. 
con ciertos contenidos no deseados cuando navegaba en ese sitio desde su casa. Cabe señalar este punto como parte de la complejidad de las estrategias metodológicas utilizadas en la investigación.

Durante el taller cada uno de los niños tenía una PC para usar libremente durante treinta minutos. En la mayoría de las experiencias se observaron situaciones en las que aquellos que tenían más experticia ayudaban espontáneamente a los que se encontraban con dificultades. En otros casos, se aburrían de jugar solos y se sentaban junto a algún compañero para jugar de a dos. Estas situaciones revelaban una forma de aprender computación colaborativa y lúdica.

Ante este escenario, se pusieron de manifiesto creencias del sentido común, compartidas por los docentes adultos en la mayoría de países, que acusan a las tecnologías de «aislar» a los niños y de esclavizarlos a las máquinas. También se expresan nostalgias y angustias frente a la -supuesta- pérdida de los juegos grupales y del compartir cara a cara, propios de otro tiempo.

El hecho es que a medida que el acceso a las computadoras y a internet se extiende, su uso se formaliza, se institucionaliza, se domestica, se confina al ámbito privado. En este sentido es fundamental preguntarnos: ¿Hay espacios para el juego libre y compartido en el ámbito escolar? ¿Será posible para las instituciones educativas reco- nocer el potencial creativo y pedagógico de las instancias de juego en contextos tecnológicos?

En la investigación realizada se encontró que jugar es la principal actividad que realizan los niños y las niñas en internet, que la página que más visitan es el portal de alojamiento de videos YouTube, y que el visionado de videos en línea es su actividad preferida en internet. En este artículo pretendemos profundizar el análisis de estos hallazgos a partir de la categoría de consumo, con especial atención a la dimensión cultural del juego en contextos tecnológicos.

\section{Jugar en contextos tecnológicos}

Con «jugar en contextos tecnológicos» no nos referimos solamente a los videojuegos de consola, o juegos online alojados en sitios especialmente diseñados para ello, sino a las prácticas lúdicas que niños y niñas realizan en internet. Estas prácticas incluyen también la búsqueda y el visionado de videos en YouTube, la búsqueda de fotos a través de Google imágenes o la búsqueda en Google de diversos contenidos. Es decir, hablamos del uso lúdico de todo tipo de aplicaciones digitales, estén o no diseñadas para esos fines.

Desde las ciencias sociales, el juego ha sido reconocido como un espacio en el que los niños incorporan pautas y reglas sociales, una instancia de socialización. El juego ha estado en la agenda de la investigación antropoló- 
gica desde sus inicios. En las últimas décadas es notable la contribución hecha por Brian Sutton-Smith (1997), fundador de la Association for the Anthropological Study of Play (en línea), quien realizó distintos tipos de estudios comparativos sobre prácticas lúdicas.

Coincidimos con la antropóloga argentina Noelia Enriz en que

[...] la producción, reproducción y reinvención de la cultura encuentra un momento particular en la infancia, un tiempo en que ciertos conocimientos son pensados como primeros (2001: 109).

En consecuencia, nos interesa indagar en estas prácticas infantiles ya que son parte del proceso en el que los niños construyen su subjetividad.

En términos generales, los videojuegos implican una narración que simula la dinámica de las interacciones sociales y afectivas (Levis y Esnaola 2008) y proponen relatos y espacios para la apropiación y resignificación de sentidos. Este es un punto importante a tener en cuenta cuando se discute la inclusión digital, como una cuestión de acceso a herramientas tecnológicas y se ignora el aspecto que concierne a la formación de la subjetividad.

En términos de género, encontramos que el contenido de los videojuegos comerciales que los niños y las niñas seleccionan muchas veces afirma virtualmente estereotipos. Así, en la página Juegos de Chicas (en línea), y en otras similares, se asocia a los juegos de vestir, maquillar, cocinar o peinar con los gustos y prácticas de las niñas. La asociación de las niñas con las compras, la ropa, la cocina, la belleza y las mascotas hacen una clara alusión a la mujer como objeto de admiración, maternal y consumista, en un entorno de colores pastel donde predomina el rosado.

Por otra parte, manifestando una evidente polarización, los juegos asociados con los gustos y prácticas de los niños incluyen armas, carros, luchas y fútbol. Se recurre a estereotipos de violencia y agresividad, como elementos constructores de la masculinidad infantil. Cabe señalar que en la investigación los varones demostraron tener mayor resistencia a jugar con «juegos de chicas» que las niñas a jugar con aplicaciones producidas para el sexo opuesto.

Una zona en la que estos límites se vuelven porosos son los juegos que simulan un «mundo» imitando el modelo de una sociedad en la que cada niño o niña tiene un avatar (personaje) que lo representa. Aquí los géneros se relacionan y no se los confina a roles fijos, espacios delimitados y actividades específicas. Tal es el caso de Club Penguin (en línea), de Disney, que propone diversos desafíos tanto para varones como para mujeres, o de Mundo Gaturro (en línea), de Argentina, donde los varones pueden cambiar de ropa o de peinado. Así como unos límites se diluyen, otros aparecen. Es 
decir, frente a la retirada de los estereotipos de género aparecen las diferencias en términos de clase. En los juegos mencionados (Mundo Gaturro y Club Penguin), que se eligen específicamente en los colegios $\mathrm{CA}$ y $\mathrm{CB}$, se necesita mayor experticia como internautas e incluso pueden requerir el pago con tarjeta de crédito para acceder a ciertas aplicaciones.

En el caso del Facebook, ${ }^{4}$ el 52,1 \% de los niños afirmó utilizar dicha red social. Los usuarios generalmente tienen cuentas abiertas por sus familiares. Los niños no usuarios, por lo general, dicen ante sus pares que no tienen una cuenta porque no les interesa, mientras otros argumentan que se debe a una prohibición expresa de sus padres. Pareciera que el contar o no con una cuenta en Facebook instaura diferencias entre los niños, al marcar simbólicamente el grado de madurez frente a sus pares.

Acceder a una red social diseñada para mayores de trece años actúa como una especie de rito de pasaje hacia una nueva etapa de la infancia, ya que representaría una garantía de haber adquirido la confianza adulta sobre la capacidad de administrarse en forma responsable en las redes sociales. Frente a ello, se entiende que existan resistencias de parte de algunos niños para decir que el acceso les ha sido prohibido por sus padres.
Aunque no se da en todos los casos, prefieren afirmar que no les interesa.

Los usuarios de Facebook dirigen su atención en su mayoría a las aplicaciones/juegos como Pet Society, Monkey Quest y City Ville, es decir que la utilizan como servicio de juegos más que como red social propiamente. En Facebook también se evidencia una diferencia en la apropiación de contenidos en términos de clase. En todos los países trabajados, varios niños y niñas, aunque no la mayoría, sobre todo de sectores $\mathrm{CA}$ y $\mathrm{CB}$, contaban con un perfil pero muy pocos accedían en los colegios del nivel C. Lo mencionado indica una correspondencia entre clase social, acceso a internet y capital simbólico.

Distintos estudios que siguen la línea de Bourdieu han hecho hincapié en la «lucha por los medios de distinción» que se batalla en el consumo, como arena en la que se reproduce la diferencia y la desigualdad. Sin embargo, como menciona García Canclini:

Si los miembros de una sociedad no compartieran los sentidos de los bienes, si solo fueran comprensibles para una elite o una minoría que los usa, no servirían como instrumentos de diferenciación (García Canclini 2004: 2).

Es en este sentido, en términos de acceso, que los juegos mencionados, entendidos como bienes de consumo, se convierten en medios de distinción

4 En teoría, para abrir una cuenta en la red social Facebook se debe contar con mayoría de edad. 
que les sirve a los niños para ubicarse en el espacio de las diferencias.

Si atendemos a la dimensión simbólica del consumo y a las fronteras que pueden establecerse a partir de las prácticas, cabe preguntarse si existen otros espacios donde esas lógicas son, al menos en apariencia, diferentes. Tal es el caso de YouTube.

\section{Jugar en YouTube}

La confluencia de la lógica del mercado y de la industria cultural se articula en el mundo actual con la lógica de la participación y la interactividad que propone la Web 2.0, donde «prosumidores», ${ }^{5}$ productores y consumidores de contenidos comparten un ambiente alternativo, paralelo a los medios masivos pero retroalimentado por estos.

Desde la antropología visual, reconocemos el trabajo de Ardevol y San Cornelio (2007), que indaga en las producciones que publican los usuarios en YouTube $^{6}$ atendiendo a la nueva articulación entre producción y consumo. Siguiendo esa línea de trabajo, argumentamos que la producción de videos para su publicación en este sitio abre un nuevo escenario para los sujetos, diferente al de la industria cultural.

A diferencia de los juegos preestablecidos y estructurados, YouTube no es un juego, pero los niños juegan a buscar videos y vinculan los contenidos más activamente con sus fantasías y deseos, por tanto puede ser entendido como un espacio de creación y recreación. Mientras tanto, los niños se entretienen, participan de la cultura popular y se introducen en el mundo del mercado como potenciales consumidores.

El consumo de la televisión se complementa y a veces compite con el consumo de internet, más específicamente con el de videos en YouTube. ¿Cómo compite? Lo hace en tanto internet no está anclado ni espacial, ni temporal, ni temáticamente. Esto permite que los niños puedan ver en la red lo que ven a través de la televisión, sin ceñirse a un horario específico, las veces que quieren. La autonomía ofrecida al usuario, tendencia de los nuevos medios y tecnologías de la información y la comunicación, es justamente uno de los aspectos que más les gusta del YouTube. Ahora bien, ¿qué hacen exactamente los niños y las niñas con los videos?

5 El término 'prosumir' alude a los usuarios que producen y consumen contenidos.

6 YouTube, programa de alojamiento de videos en internet, fue fundado en el año 2005. Este sitio permite a sus usuarios colgar, ver y compartir vídeos. Muy a pesar de las restricciones de las reglas de copyright que limitarían los contenidos a las autoproducciones, es posible encontrar en YouTube «clips de películas, programas de televisión, anuncios o documentales y parodias o re-elaboraciones amateur de estas producciones profesionales, la mayoría muy populares» (Ardevol y San Cornelio 2007: 6). 
Para introducirnos en el tema y entender la relación entre los niños y los videos del YouTube, siguiendo a Winnicott (1999), es necesario establecer una diferencia entre el juego (game) de la actividad del jugar (play). La diferencia radica en que mientras el juego puede implicar el seguimiento de una serie de secuencias ordenadas y programadas, la actividad del jugar es mucho más libre y creativa.

En la misma línea, Roger Callois (1986) distingue dos tipos de juego: la paidia como el juego libre, sin dirección, y el ludus como el juego reglado. En el caso de nuestro trabajo esta distinción nos permite atender a las particularidades de la interacción de los niños y las niñas con los juegos «reglados» que produce la industria cultural y el uso lúdico de plataformas diseñadas para el entretenimiento, del que los niños se apropian de un modo más «libre».

El hecho de no haber sido diseñado como juego no significa que YouTube no tenga reglas. La regla consiste en buscar un tipo de video que divierta a quien lo busca y a sus acompañantes. También es parte de la actividad lúdica el repetir el video o abrir otro similar de los que están en la lista, haciendo una especie de compilado entre las sugerencias que ofrece el sitio y otros videos.
Las opciones que los niños buscan son limitadas, sin embargo hay más margen para la agencia que en la televisión. ¿Cuál es entonces la diferencia entre YouTube y el control remoto? Una de las diferencias es que en YouTube los contenidos son producidos por los usuarios y en el acceso y selección de este tipo de contenidos hay un margen de creatividad que los medios masivos no ofrecen. Por otro lado, los videos que miran, recrean y comparten los niños son del tipo casero, que ellos podrían producir eventualmente.

Al mismo tiempo, cabe destacar que los contenidos producidos por los usuarios de YouTube no están despojados de discursos hegemónicos. Están impregnados de lógicas propias del capitalismo, ya que el productor de contenidos tiene en cuenta al espectador desde el momento mismo de su producción y los videos suelen ser ideados para ser difundidos. Ahora bien, ¿qué tipo de videos miran los niños y las niñas en YouTube? ¿Hay espacio para que pongan en juego sus saberes y experiencias mientras exploran nuevos horizontes de sentido?

\section{Temas transversales: parodias, terror y sexo ${ }^{7}$}

Encontramos tres temáticas transversales en los videos que miran en

7 Las descripciones incluidas en esta sección han sido obtenidas a partir de la observación de los talleres de navegación libre, en el cual participaron niños y niñas de tercer grado 
YouTube los niños de todos los países: las parodias de los héroes, el terror y el sexo; que son las más presentes en las observaciones y conversaciones sobre las cuales los niños coinciden, ya sea al demostrar su gusto o su rechazo.

\section{Parodias de videos: I a vulnerabilidad de los héroes}

Los videos que parodian dibujos animados aparecen en el estudio en reiteradas oportunidades. Son videos que se producen utilizando softwares de edición que se instalan en cualquier computadora. Incluso es posible encontrar varias versiones de un mismo video, en inglés, subtitulado en idioma castellano y también perfectamente doblado. Solo unos pocos empiezan con una medida de precaución, advirtiendo que su contenido no es apto para niños.

En una simple búsqueda en YouTube de los personajes populares Bob Esponja y Dora la Exploradora, por solo citar dos ejemplos, es posible encontrar resultados completamente diferentes a las dulces y tiernas imágenes asociadas con ellos.

Dora y Bob son parodiados invirtiendo sus características personales.
Así, la primera pasa de ser la niña exploradora a transformarse en Dora la Violadora (en línea), Dora la Matadora (en línea) o Dora la Exploradora Asesina (en línea). También se burlan de ellos alterando sus comportamientos habituales. Por ejemplo, a Bob se le presenta drogado, fumando crack y robando para comprar marihuana (en línea). Mientras, Dora es alejada del bosque y reubicada en insólitos lugares, como en un prostíbulo y una tabaquería a donde acude a comprar cigarros. ${ }^{8}$

La temática de estos videos juega con lo que ni remotamente estarían vinculados sus protagonistas. Los presentan como personajes alejados de la idílica imagen de la inocencia y bondad. Como antihéroes, Dora y Bob son retratados en toda su vulnerabilidad, poseídos por vicios, gustos, costumbres, que están asociadas al mundo adulto, pero que en la vida real también afectan muchas veces a la infancia.

$\mathrm{Al}$ encarnarse, los dibujos animados dejan de ser inmortales. Tanto Bob como Dora son confrontados crudamente con la muerte, en varias versiones. Bob muere en una balacera con sus amigos de la serie; Dora es asesinada por Bob en venganza porque ella, a

de primaria, es decir de 8 años de edad, y están incluidas en el informe del capítulo 3. Internet: perfiles de internautas, gustos, preferencias y percepciones, sección 3.8 del documento Investigación comparativa regional sobre los usos y disfrute de Internet por niñ@s de entre 8 y 10 años, en tres colegios de Argentina, Perú y Paraguay (Trinidad y Rodríguez 2012).

8 Existen en YouTube varias versiones de Dora la Exploradora y su relación con las situaciones descritas; por ejemplo, el titulado Dora la Exploradora y el prostíbulo (no apta para niños) (en línea). 
su vez, mató a su juguete favorito. Ella también es asesinada con una ametralladora por un zorro de la serie en venganza por la muerte de sus padres. Todos contra todos en una eclosión de violencia y sangre.

Un análisis posterior del material, a efectos de la presente ponencia, nos permite argumentar que en la parodia de los videos la subalternidad no está presente en el consumo como práctica creativa sino en la producción misma de los contenidos, que subvierte la lógica original de los dibujos animados.

Los niños espectadores se convierten de algún modo en «cómplices» de los autores, quienes recrean según sus propios parámetros a los productos de la industria cultural.

\section{Terror, fantasmas y apariciones}

Los niños y las niñas tienen un sentimiento ambivalente de miedo y gusto frente a los videos de terror. El impacto es tal que incluso tienen pesadillas, como dijo un niño de Argentina-CC, que después de verlos tenía «terror en el corazón». Hay quienes no están interesados en buscar intencionalmente este tipo de temas ni experimentarlos; sin embargo, mientras navegaban se han encontrado con imágenes no deseadas de terror. Tal es el caso de una niña de Argentina-CC, quien involuntariamente se encontró con imágenes de terror que eran «de matar» que la asustaron, causándole una gran impresión y una inacción frente a lo que estaba viendo. Se trataba de unas imá- genes guardadas en la computadora que, para cerrarlas, tuvo que llamar a su hermano en su ayuda.

El interés por la temática del terror y la emoción de miedo, combinada con risas, se observó en la búsqueda que los niños hicieron del video El fantasma de los Simpsons, en Perú-CB. Este tiene una duración de veinticuatro segundos y se inicia con la pregunta «¿Ves al fantasma? Súbele todo el volumen a la compu» [sic], posteriormente aparece la imagen animada de Bart Simpson con un amigo; es una imagen estática, sin ruido. A partir del segundo 18 aparece repentinamente la imagen de un hombre real agrietado y con una mueca de terror, junto con un ruido, que, escuchado a todo volumen, se asemeja a una tremenda ruptura de vidrios. Este caso no es el único, hay otros videos que asustan, referidos por los niños, que mezclan diversos géneros, desde los zombies, de moda actualmente, hasta los fantasmas y sirenas malas.

En el uso que hacen los niños de los contenidos de YouTube surgen interpretaciones en las que saberes y creencias locales se ponen en juego. Tal es el caso de La Llorona, leyenda presente en varios países latinoamericanos sobre una mujer "aparecida», que convertida en un alma penitente asusta con su llanto a quienes la escuchan.

En el contexto de las nuevas tecnologías, La Llorona ha cambiado su ámbito de acción al espacio virtual. Así lo relata un niño de Argentina-CC, al 
que se le apareció mientras escribía en el motor de búsqueda el nombre del grupo musical Los Wachiturros. Es interesante destacar que este tipo de experiencias provienen de un colegio donde la matrícula tiene un $75 \%$ de niños de familias migrantes de países limítrofes, especialmente de Bolivia. Es posible, entonces, que el conocimiento que los niños tienen sobre la leyenda de La Llorona lo hayan adquirido a través de la transmisión de su familia. En el noroeste argentino y en las zonas rurales de Bolivia y del Perú los mitos y las leyendas de este tipo son parte del repertorio de interpretaciones de las experiencias de la vida cotidiana.

Este caso nos lleva a preguntarnos por la dimensión intercultural y los modos en que se articulan simbólicamente las trayectorias migratorias con la participación en la cultura globalizada. También nos interpela sobre los procesos de tensión entre las identificaciones con experiencias familiares y las que surgen en el ámbito del consumo cultural.

\section{Sexo}

Entre los niños varones está muy difundido el gusto por los llamados videos Bananeros ${ }^{9}$ y los videos de Vete a la Versh (en línea), ambas son produc- ciones animadas de humor negro que montan diálogos sobre videos originales de personajes de la cultura popular, e insertan imágenes con contenido sexual, de corte soez y vulgar. Tanto la alusión a la banana como a la versh ${ }^{10}$ tienen connotaciones sexuales.

Es justamente la imagen del pene la que se observa claramente en el logotipo de la producción. El discurso visual y escrito nos da una pauta del contenido de los videos, los cuales poseen una advertencia que dice: «Esta obra está dirigida a un público maduro, pues contiene temas que pueden ofender a individuos de criterios distintos. El objetivo de esta obra no es más que entretener».

Además, se ha identificado que los niños que buscan activamente este tipo de videos se ubican en colegios de CA, tanto en Argentina como en el Perú. El conocimiento de este tipo de videos es transmitido muchas veces por parte de los amigos mayores, y dado el humor que manejan y las alusiones sexuales que hacen tienen mucho éxito entre los niños que están en periodo de latencia y despertando al camino hacia la pubertad. Así, en uno de los colegios se observó que los niños estaban muy interesados en ese tipo de videos, los buscaron y en-

9 Este es el caso de la productora de videos El Bananero, que ha creado videos como Harry Potter bananero (en línea).

10 El término alude a la palabra 'verga', derivada del latín virga, que significa pene. 
contraron en YouTube, muy a pesar del filtro con que contaba el centro de cómputo.

Mientras que a algunos les gustan y los buscan, como hemos visto, a otros los videos de temas relativos al erotismo, el sexo y los desnudos no les gustan. Varios coinciden en referir su desagrado por la aparición de contenido no deseado de índole sexual; algunos de ellos se refieren específicamente a la pornografía, que aparece en forma de publicidad mientras navegan. Ciertamente, la emergencia de este tipo de imágenes se configura como una agresión contra el internauta, pues irrumpe de improviso y sin que haya sido buscado. Al respecto, un niño de Argentina-CA cuenta que buscando una canción que le encantaba encontró imágenes de «chicas sin bikini». Otro niño, en este caso de Argentina$\mathrm{CB}$, mencionó que no le gustan algunos videos de los Wachiturros ${ }^{11}$ porque «ponen a mujeres desnudas».

El video al que se refiere este último niño no está identificado; no obstante, en el video oficial de la canción más conocida del mencionado grupo, Tirate un paso, aparece una joven bailando sensualmente; aunque ella no se desnuda, muestra sugerentemente su trasero, dejando ver breves partes de su ropa interior. La performance visual de la joven va de acuerdo con la letra de la canción, que tiene referencias corporales, sexuales y eróticas en jerga. Sin embargo, cabe anotar que es lo visual, antes que lo discursivo, lo que el niño mencionado identifica como lo que le disgusta, las imágenes de mujeres desnudas, y no la letra de la canción, que metafóricamente desnuda a las mujeres.

Varios niños de Paraguay-CA son directos y manifiestan que internet les permite ver «chicas lindas», «chicas en bikini», «cositas lindas», y al decirlo desatan muchas risas. Pero no siempre los niños son tan abiertos para hablar de esos temas. Los que sí, generalmente lo hacen con vergüenza y en voz muy baja, casi al oído del interlocutor, haciendo interesantes revelaciones.

La vergüenza y el temor de manifestar interés por la sexualidad aún se conservan, lo que indicaría que este tema todavía es tabú. Por ejemplo, en Paraguay CB un niño comentó sobre lo que no le gusta de internet: «no sé si lo puedo decir, pero no es algo de malas palabras, cuando aparecen cosas de ir a la cama...». Contó también que una vez encontró algo que le dio mucha risa, que eran dos bichos en la cama y lo sacó rápido. El facilitador le preguntó si lo sacó porque le dio vergüenza, pero otro niño interrumpió la conversación cuestionando a su compañero: «¿O porque apareció mamá?». Esta

11 Grupo de música popular argentino. 
pregunta complementa la vergüenza con la posibilidad de que, además, se pueda ser descubierto por un adulto en el despliegue de su curiosidad por temas sexuales. En el interés por la sexualidad y el gusto por determinadas temáticas relacionadas con esta se ponen de manifiesto asociaciones de género. Son los niños varones, con la sola excepción de una niña, los que se pronuncian sobre esos temas y la pornografía está siempre asociada con el desnudo del cuerpo femenino.

Sin embargo, sería un error pensar que internet es la única fuente de información sobre sexo. En la investigación se revelaron dos casos en los que los familiares eran consumidores de pornografía en internet, quienes fueron identificados por los niños como poseedores y degustadores de ese tipo de contenidos, tanto en sus computadoras personales como en sus dispositivos móviles.

Tal como se desprende del caso relatado, la exposición a este tipo de contenidos puede provenir de la propia casa y no ser un efecto unívoco de la navegación en internet.

En términos generales, hemos apreciado que los niños y las niñas no solo buscan videos, sino que también satisfacen su curiosidad, hacen y crean una razón para jugar. Cuando en la sociedad de consumo el juego y el jugar no son ajenos a las lógicas que impone el mercado, se hace necesario encauzar las indagaciones en el tema a la luz de las nuevas problemáticas y nuevos espacios.

\section{Reflexiones finales}

Partimos de la idea de que la navegación en internet y el consumo de productos culturales constituye una experiencia formativa para los niños en relación con la inmersión en el mundo del consumo. Cabe destacar el hecho de que los niños no son espectadores pasivos ni desconocen la dimensión comercial de los juegos a los que acceden en internet.

En varias situaciones diferentes niños y niñas se mostraron críticos, en la investigación, con respecto a la publicidad que encuentran o que emerge al navegar, por considerarla engañosa e intrusiva. Lo primero, porque les ofrece interesantes lugares virtuales gratuitos para jugar y posteriormente les cobra para ingresar; lo segundo, porque interrumpen su concentración mientras están jugando.

El estudio mencionado reveló que existe una tendencia a encontrar una mayor cantidad de navegantes expertos en los colegios de nivel socioeconómico alto. Aunque reconocemos como fundamental el hecho de contar con una computadora en el hogar para adquirir experiencia, también registramos la importancia del acompañamiento y la guía de un adulto, hermano o amigo en este proceso. 
Pensamos que existe un margen creativo en las prácticas de consumo y que estas no siempre son multiplicadoras de un orden dado sino productoras de re-significaciones y nuevos sentidos. No obstante, el reconocimiento de la agencia de los sujetos en la formación de su subjetividad no convierte el proceso automáticamente en un acto de resistencia. Si bien reconocemos que las opciones culturales de las clases populares son condicionadas y limitadas, estas «[...] seleccionan y combinan los materiales recibidos -en la percepción, en la memoria, y en el uso- y construyen con ellos como el bricoleur, otros sistemas que nunca son el eco automático de la oferta hegemónica» (García Canclini 1984: 7).

\section{Bibliografía}

América Económica. «Países latinoamericanos con mayor crecimiento en el 2011». <http://www.americaeconomia.com/economia-mercados/ finanzas/conozca-los-cinco-paiseslatinoamericanos-con-mayor-crecimiento-en-2011>. [Consulta: 15 de octubre del 2012].

Anderson, Benedict (1992). Comunidades imaginadas. México: Fondo de Cultura Económica.

Appadurai, Arjur (2001). La modernidad desbordada: dimensiones culturales de la globalización. Montevideo: Trilce.

Ardevol, Elisenda y Gemma San Cornelio (2007). «Si quieres vernos en acción: YouTube.com. Prácticas mediáticas y autoproducción en Internet». Revista Chilena de Antropología Visual 10. Santiago de Chile. <http://www.antropologiavisual.cl/ imagenes10/imprimir/ardevol_\&_ san_cornelio.pdf $>$. [Consulta: 29 de octubre del 2012].

Bob Esponja drogado, con subtítulos en castellano. YouTube. Video $<$ http://www.youtube.com/watch? $\mathrm{v}=$ CsTDfR1znuc\&feature $=$ related $>$. Consulta: 29 de octubre del 2012].

Bob Esponja drogado, doblado al castellano y subtitulado. YouTube. Video. <http://www. youtube.com/w at ch? v =uZ_ Bn4BMBAQ\&feature $=$ related $>$. [Consulta: 29 de octubre del 2012].

Bob Esponja drogado, en inglés: SpongeBong HempPants episode 2. YouTube. Video. <http://www.youtube. com/watch?v=wnY4mZDSq3g>. [Consulta: 29 de octubre del 2012].

Caggiano, Sergio (2005). Lo que no entra en el crisol. Inmigración boliviana, comunicación intercultural y procesos identitarios. Buenos Aires: Prometeo.

Caillois, Roger (2000 [1960]). I giochi e gli uomini: la maschera e la vertigine. Milán: Bompiani.

Club Penguin. Disney. <http://www. clubpenguin.com/es/>. [Consulta: 29 de octubre del 2012].

Dora la exploradora asesina. YouTube. Video. <http://www.youtube.com/ watch? $\mathrm{v}=\mathrm{bNBqPSfIStA}>$. [Consulta: 29 de octubre del 2012]. 
Dora la exploradora y el prostíbulo (no apta para niños). YouTube. Video. <http://www.youtube.com/ watch?v=UhuJdZTQcDg>. [Consulta: 29 de octubre del 2012].

Dora la matadora. YouTube. Video. $<$ http://www.youtube.com/watch? v=x59_P_FUi4I $>$. [Consulta: 29 de octubre del 2012).

Dora La violadora. YouTube. Video. $<$ http://www.youtube.com/ $\mathrm{w}$ a t ch? $\mathrm{v}={ }_{-} \mathrm{xKw} 2 \mathrm{f} \mathrm{N7a} \mathrm{oM>.}$ [Consulta: 29 de octubre del 2012].

El Bananero. Productora de videos. <http://www.elbananero.com/>. [Consulta: 29 de octubre del 2012].

El Bananero. Harry Potter bananero. YouTube. Video. <http://www.youtube.com/watch?v=1j3k9LMWsBs $>$. [Consulta: 29 de octubre del 2012].

Enriz, Noelia (2011). «Antropología y juego: Apuntes para la reflexión». Cuadernos de Antropología Social 34. Buenos Aires: FFL-UBA. <http://www.scielo.org.ar/pdf/cas/ n34/n34a05.pdf $>$. [Consulta: 29 de octubre del 2012].

García, Vilma (2011). «Países latinos con mayor crecimiento económico: análisis y perspectivas». Coyuntura Económica. <http://coyunturaeconomica.com/economia-latinoamerica/ paises-latinos-con-mayor-crecimiento-economico>. [Consulta: 29 de octubre del 2012].

García Canclini, Néstor (2004). «El consumo sirve para pensar», en Bolbin, Mauricio y Ana Rosato (eds.). Cons- tructores de otredad. Buenos Aires: Antropofagia.

García Canclini, Néstor (1984). «Gramsci con Bourdieu. Hegemonía, consumo y nuevas formas de organización popular». Nueva Sociedad 71.

Gil, Adriana; Feliu, Joel; Rivero, Isabel y Eva Patricia Gil (2003). «¿Nuevas tecnologías de la información y la comunicación o nuevas tecnologías de relación? Niños, jóvenes y cultura digital». UOC. <http://www.uoc. edu/dt/20347/index.html>. [Consulta: 29 de octubre del 2012].

Grimson, Alejandro (2011). Los límites de la cultura. Crítica de las teorías de la identidad. Buenos Aires: Siglo XXI Editores.

Juegos de Chicas.com. Página web. $<$ http://www.juegosdechicas.com/>. [Consulta: 29 de octubre del 2012].

Levis, Diego y Graciela Alicia Esnaola (2008). «La narrativa en los videojuegos: un espacio cultural de aprendizaje socioemocional». Revista Electrónica Teoría de la Educación. Educación y Cultura en la Sociedad de la Información. Universidad de Salamanca. <http://campus. usal.es/ teoriaeducacion/rev_numero_09_03/n9_03_esnaola_levis. pdf $>$. [Consulta: 29 de octubre del 2012].

Miniwatts Marketing Group. «Latin American internet usage statistics». <http://www.internetworldstats. com/stats10.htm>. [Consulta: 6 de febrero del 2012]. 
Mundo Gaturro. Juego online gratuito para niños. $<\mathrm{http}: / / \mathrm{w} w \mathrm{w} \cdot \mathrm{mundoga}-$ turro.com/>. [Consulta: 29 de octubre del 2012].

Nugent, Guillermo (1996). El poder delgado. Fusiones, lejanías y cercanías en el diseño cultural peruano. Lima. Fundación Friedrich Ebert.

Papalini, Vanina (2008). «Cultura masiva y subjetividad. Huellas del proceso de mundialización en marcha». Ponencia presentada en el $X$ Congreso Redcom «Conectados, hipersegmentados y desinformados en la era de la globalización». 4, 5 y 6 de setiembre del 2008. Salta: Universidad Católica de Salta, Facultad de Artes y Ciencias.

Prensky, Mark (2001). «Digital natives digital inmigrants». On the Horizon MCB University Press. Vol. 9, núm. 5.

Sádaba Chalezquer, Charo y Xavier Bringué Sala (2009). Niños y adolescentes españoles ante las pantallas: rasgos configuradores de una generación interactiva. Navarra: Universidad de Navarra.

Soto Calderón, Andrea (2007). «Identidad y diversidad: De la cultura local a la global». Entrevista a Renato Ortiz. Revista Austral de Ciencias
Sociales. Universidad Austral de Chile, Facultad de Filosofía y Humanidades, Instituto de Ciencias Sociales.

The Association for the Study of Play (Tasplay). <http://tasplay.org/>. [Consulta: 29 de octubre del 2012].

Trinidad, Rocío y Víctor Rodríguez (2012). Investigación comparativa regional sobre los usos y disfrute de Internet por niñ@s de entre 8 y 10 años, en tres colegios de Argentina, Perú y Paraguay. Save the Children, Oficina Regional para América Latina y el Caribe. Suecia.

Vázquez Villanueva, Graciana (s/f). «La comunidad que viene. Los ciudadanos analizan la televisión». Comité Federal de Radiodifusión. Publicaciones digitales (Comfer). $<$ http://industriasdecontenido. files.wordpress.com/2010/08/argcomfer-la-comunidad-que-vienelos-usuarios-analizan-la-tv1.pdf $>$. [Consulta: 11 de agosto del 2013].

Vete a la Versh. YouTube. Video. $<w w w$. vetealaversh.com>. [Consulta: $29 \mathrm{de}$ octubre del 2012].

Winnicott, Donald (1999). Realidad y juego. Buenos Aires: Gedisa. 